\title{
Inhibitory effect of zinc on the advanced glycation end product-induced apoptosis of mouse osteoblastic cells
}

\author{
MINGYUE XIONG, LIQIANG LIU, ZHENHUI LIU and HANGFEI GAO
}

\begin{abstract}
Department of Traumatic Surgery, Xinqu Hospital, The First Affiliated Hospital of Henan University of Science Technology, Luoyang, Henan 471000, P.R. China
\end{abstract}

Received September 21, 2014; Accepted June 5, 2015

DOI: $10.3892 / \mathrm{mmr} .2015 .4088$

\begin{abstract}
Osteoporosis and diabetes have become serious health problems worldwide. Previous studies have suggested that diabetes is associated with osteoporosis and increased fracture risk. However, the mechanism underlying diabetes-induced osteoporosis remains to be elucidated. Therefore, the present study aimed to examine the mechanism underlying diabetes-induced osteoporosis, and determine the protective effects of zinc, which is known to be closely associated with osteoporosis and diabetes. The results of the present study demonstrated that zinc inhibited advanced glycation end product (AGE)-induced MC3T3-E1 cell apoptosis by attenuating the production of reactive oxygen species, inhibiting caspase- 3 and caspase- 9 activation, and inhibiting the release of cytochrome $c$ from between the mitochondria and the cytosol. Furthermore, zinc was found to protect cells against AGE-induced apoptosis via the mitogen-activated protein kinase/extracellular signal-regulated kinase and phosphoinositide 3-kinase/AKT signaling pathways. In conclusion, these findings enable a better understanding of the mechanism underlying diabetes-induced osteoporosis, and may indicate a novel target for its prevention and treatment.
\end{abstract}

Correspondence to: Mr. Mingyue Xiong, Department of Traumatic Surgery, Xinqu Hospital, The First Affiliated Hospital of Henan University of Science Technology, 636 Guanlin Road, Luoyang, Henan 471000, P.R. China

E-mail: mingyue_14_8@163.com

Abbreviations: ROS, reactive oxygen species; PI, propidium iodide; MTT, 3-[4,5-dimethylthiazol-2-y]-2,5-diphenyltetrazolium bromide; BSA, bovine serum albumin; DMSO, dimethyl sulfoxide; AGEs, advanced glycation end products; DCF-DA, 2,7-dichlorofluorescein-diacetate; TBS, tris-buffered saline; $\alpha$-MEM, $\alpha$-minimal essential medium

Key words: zinc, advanced glycation end products, apoptosis, reactive oxygen species, extracellular signal-regulated kinases, AKT

\section{Introduction}

In recent years, the incidence of diabetes mellitus and osteoporosis has increased, as a result of longer life expectancy and a lifestyle characterized by low levels of physical activity and increased high-energy food intake (1). Osteoporosis, which is the most common type of bone disease, is associated with low bone mineral density (BMD) and systemic impairment of bone mass, strength and microarchitecture, which increases the propensity of fragility fractures (2). Osteoporosis is clinically defined as having a BMD $\geq 2.5$ standard deviations below the young female adult mean (T-score, -2.5) (3). The etiology of osteoporosis is attributed to various endocrine, metabolic, and mechanical factors, and can occur at any age; however, it is predominantly diagnosed in elderly and diabetic patients (4). Diabetes mellitus is a risk factor for osteoporotic fractures. Diabetes mellitus affects bone metabolism, and may lead to osteopenia and osteoporosis $(5,6)$. The causes of diabetes-induced osteoporosis are varied, and include insulin deficiency, disordered calcium-phosphate metabolism and excessive secretion of parathyroid hormone (7-9). However, the underlying molecular link between diabetes and osteoporosis remains to be elucidated.

In patients with diabetes mellitus, during long-lasting hyperglycemia, glucose forms covalent adducts with plasma proteins through a non-enzymatic process, the products of which are termed advanced glycation end products (AGEs) (10). AGEs may be critical mediators in the pathogenesis and development of osteoporosis and other age-associated chronic degenerative diseases (11). The present study aimed to determine whether AGEs serve as a causal link between diabetes and osteoporosis.

Zinc, which is an essential nutritional factor in the growth of humans and animals, has been considered a novel supplementation factor in the prevention and treatment of osteoporosis (12). A previous study demonstrated that zinc was able to inhibit high glucose-induced apoptosis by suppressing oxidative stress in renal tubular epithelial cells (13). Furthermore, zinc supplementation has been observed to exert positive effects in diabetes, including a modest, but significant, reduction in fasting glucose, and a trend towards decreased glycated hemoglobin (14). The present study aimed to use the MC3T3-E1 mouse osteoblastic cell line to investigate the role of zinc in AGE-induced cell apoptosis, as well as investigate novel ways to treat diabetes-induced osteoporosis. 


\section{Materials and methods}

Reagents. $\alpha$-minimal essential medium ( $\alpha$-MEM), penicillin/streptomycin $(5,000 \mathrm{U} / \mathrm{ml}$ penicillin; $5,000 \mathrm{U} / \mathrm{ml}$ streptomycin) and fetal bovine serum (FBS) were obtained from Gibco Life Technologies (Grand Island, NY, USA).ZnSO, ,MTT,PD98059,LY294002, Triton X-100, bovine serum albumin (BSA) and dimethyl sulfoxide (DMSO) were purchased from Sigma-Aldrich (St. Louis, MO, USA). Mouse monoclonal IgG anti-caspase 3 (sc-65496), anti-caspase 9 (sc-56073), anti-B-cell lymphoma 2-associated X protein (Bax) (sc-20067), anti-cytochrome $c$ (cyto-C) (sc-13561), anti- $\beta$-actin (sc-47778), anti-extracellular signal-regulated kinases (ERK) (sc-514302), anti-phosphorylated (p)-ERK (sc-377400) and anti-AKT (sc-377457) antibodies, and the rabbit polyclonal IgG anti-p-AKT antibody (sc-135650), were obtained from Santa Cruz Biotechnology, Inc. (Dallas, TX, USA). Enhanced Chemiluminescence (ECL) kit was purchased from Pierce Biotechnology, Inc. (Rockford, IL, USA). All reagents used were trace element analysis grade. All water used was glass distilled.

Cell culture. MC3T3-E1 mouse preosteoblasts (cat. no. CRL-2593; American Type Culture Collection, Manassas, VA, USA) were cultured in $\alpha$-MEM, supplemented with $10 \%$ heat-inactivated FBS and antibiotics (100 units penicillin/streptomycin) at $37^{\circ} \mathrm{C}$ in a humidified incubator containing $5 \% \mathrm{CO}_{2}$. For experiments, the cells were cultured for $24 \mathrm{~h}$ in $3 \mathrm{ml} \alpha$-MEM, supplemented with $10 \% \mathrm{FBS}$, in order to obtain monolayers. The cells were subsequently rinsed with phosphate-buffered saline (PBS), the medium was then replaced and the cells were cultured further. In order to investigate the effects of zinc on the signaling pathways of PI3K/AKT and MAPK/ERK, a specific PI3K/AKT inhibitor, LY294002 (10 $\mu \mathrm{M}$ LY294002, 1x105 cells) and a specific MAPK/ERK inhibitor, PD98059 (20 $\mu \mathrm{M}$ PD98059, $1 \times 10^{5}$ cells) were used.

Groups. The groups were as follows: Control group, MC3T3-E1 cells $\left(1 \times 10^{5}\right)$ cultured with $\alpha$-MEM, supplemented with $10 \%$ heat-inactivated FBS for 48 h; BSA group, MC3T3-E1 cells $\left(1 \times 10^{5}\right)$ treated with BSA for $48 \mathrm{~h}$; AGEs group, MC3T3-E1 cells $\left(1 \times 10^{5}\right)$ treated with $500 \mu \mathrm{g} / \mathrm{ml}$ AGEs (Anyan-bio Technology, Shanghai, China) for $48 \mathrm{~h}$; AGEs + zinc group, MC3T3-E1 cells $\left(1 \times 10^{5}\right)$ treated with $500 \mu \mathrm{g} / \mathrm{ml}$ AGEs in the presence of $50 \mu \mathrm{M} \mathrm{ZnSO}_{4}$ for $48 \mathrm{~h}$.

Cell viability. Cell viability was measured using a quantitative colorimetric MTT assay, with $1 \times 10^{5}$ cells $/ \mathrm{ml}$ in 96 -well plates. Briefly, $10 \mu \mathrm{l}$ MTT (final concentration, $5 \mathrm{mg} / \mathrm{ml}$ ) was added to the medium and the cells were incubated at $37^{\circ} \mathrm{C}$ for $4 \mathrm{~h}$. The medium was then aspirated from each well and $100 \mu \mathrm{l}$ DMSO was added to dissolve the formazan crystals. The optical density of each well was read at $492 \mathrm{~nm}$ using a microplate reader (Multiskan MK3; Bio-Rad Laboratories, Inc., Hercules, CA, USA).

Detection of intracellular reactive oxygen species (ROS) levels. The concentrations of ROS were determined based on the oxidation of 2,7-dichlorodihydrofluorescein (DCFH;
Nanjing Jiancheng Bioengineering Research Institute, Nanjing, China). Briefly, MC3T3-E1 cells $\left(4 \times 10^{6}\right)$ were incubated with $10 \mu \mathrm{mol} / 1 \mathrm{DCFH}-\mathrm{DA}$ probe at $37^{\circ} \mathrm{C}$ for $35 \mathrm{~min}$, following which the cells were washed three times with PBS to remove residual probe. DCFH-DA is deacetylated intracellularly by nonspecific esterase and is further oxidized by ROS to the fluorescent compound 2,7-dichlorofluorescein (DCF). DCF fluorescence was detected using flow cytometry with a FACSCalibur (BD Biosciences, Franklin Lakes, NJ, USA), and analyzed using Quantity One software, version 4.62 (Bio-Rad Laboratories, Inc.).

Analysis of apoptosis. To quantify the number of apoptotic cells, flow cytometry (ACCURI ${ }^{\mathrm{TM}}$ C6; BD Biosciences) was performed using a Fluorescein Isothiocyanate (FITC) Annexin V Apoptosis Detection kit (Nanjing KeyGen Biotech Co., Ltd., Nanjing, China), according to the manufacturer's instructions. The cells were resuspended in $300 \mu 11 \mathrm{X}$ binding buffer and transferred into a sterile flow cytometry glass tube. Annexin V/FITC $(10 \mu \mathrm{l})$ was added to the cells and incubated in the dark for $30 \mathrm{~min}$ at room temperature. The cells $\left(1 \times 10^{5}\right)$ were then treated with $5 \mu 1$ propidium iodide (Sigma-Aldrich), and incubated at room temperature for $10 \mathrm{~min}$ in the dark. Following incubation, the cells were analyzed using flow cytometry. The percentage of cellular apoptosis was determined using the FITC Annexin V Apoptosis Detection kit.

Western blotting. The MC3T3-E1 cells were washed with PBS, scraped, collected and lysed using ice-cold lysis buffer (Beyotime Institute of Biotechnology, Haimen, China), and centrifuged at $750 \mathrm{x}$ g for $8 \mathrm{~min}$ at $0^{\circ} \mathrm{C}$ to yield the whole cell extract. The resuspended cells were then homogenized with ten strokes of a Teflon homogenizer (PT1200E; Kinematica, Luzern, Switzerland), and the homogenates were centrifuged twice at $750 \mathrm{x} \mathrm{g}$ for $10 \mathrm{~min}$ at $4^{\circ} \mathrm{C}$. The supernatants were further centrifuged at $10,000 \mathrm{x}$ f for $15 \mathrm{~min}$ at $4^{\circ} \mathrm{C}$, to obtain the mitochondrial pellets. Cytosolic fractions were obtained following further centrifugation at $100,000 \mathrm{x}$ for $1 \mathrm{~h}$ at $4^{\circ} \mathrm{C}$. The samples were then denatured in boiling water for $5 \mathrm{~min}$, the protein concentration of cell lysates was quantified using the Bicinchoninic Acid kit (Beyotime Institute of Biotechnology) and equal amounts of protein $(10 \mu \mathrm{g})$ were separated by $10 \%$ SDS-PAGE (Sigma-Aldrich) and transferred to nitrocellulose membranes (Sigma-Aldrich). The protein concentration of cell lysates was quantified using the Bicinchoninic Acid kit (Beyotime Institute of Biotechnology) and equal amounts of protein $(10 \mu \mathrm{g})$ were separated by SDS-PAGE. The membranes were incubated overnight at $4^{\circ} \mathrm{C}$ with anti-Bax, anti-cyto-C, anti-caspase 3, anti-caspase 9 , anti-ERK, anti-p-ERK, anti-AKT, anti-p-AKT, and anti- $\beta$-actin antibodies. The antibodies were used at a dilution of 1:400 in Tris-buffered saline Tween (Sigma-Aldrich), containing $50 \mathrm{mM}$ Tris- $\mathrm{HCl}, 150 \mathrm{mM} \mathrm{NaCl}$, and $0.05 \%$ (w/v) Tween 20, ( $\mathrm{pH} 7.4)$ containing 5\% (w/v) BSA. The membranes were then incubated for $2 \mathrm{~h}$ with horseradish peroxidase-conjugated anti-rabbit or anti-mouse secondary IgG antibodies (1:1,000; Santa Cruz Biotechnology, Inc.) at room temperature. The immunoreactive bands were visualized using an ECL kit. 
A

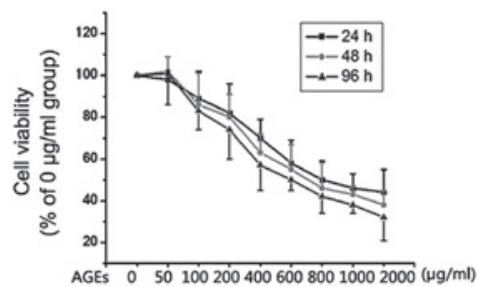

B

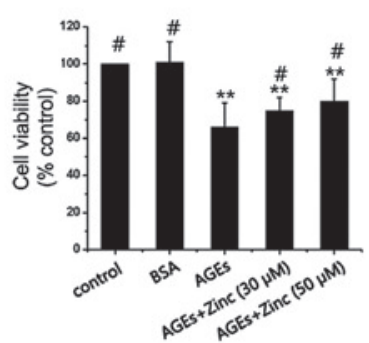

C
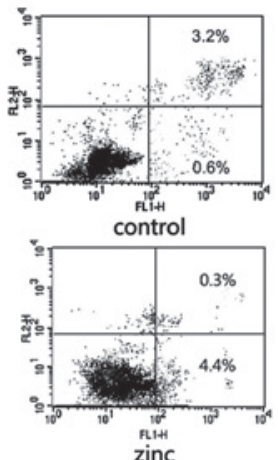

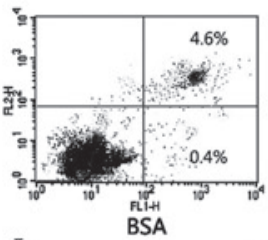

D
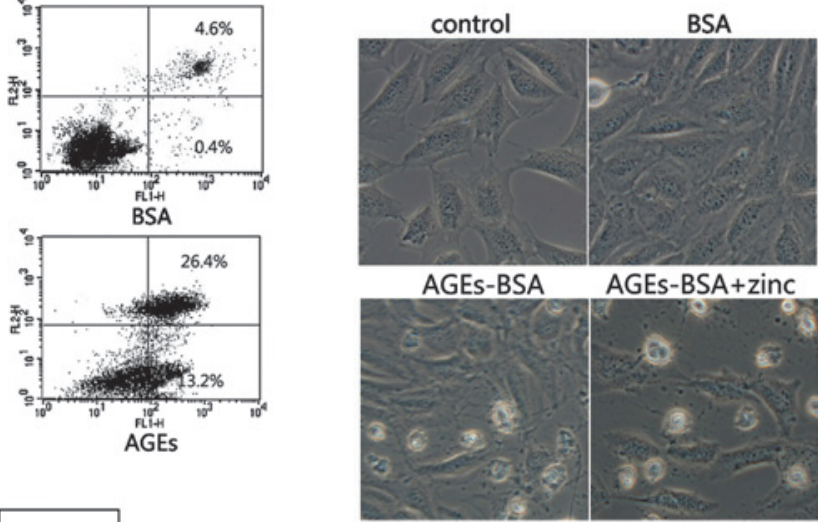

$\mathbf{E}$

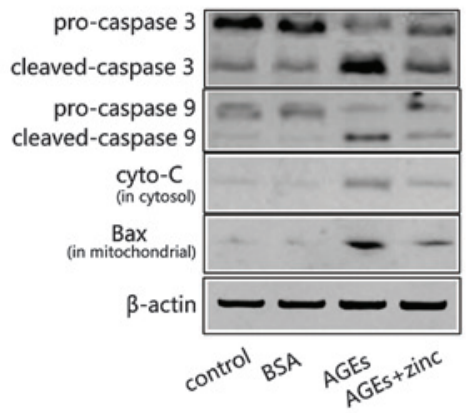

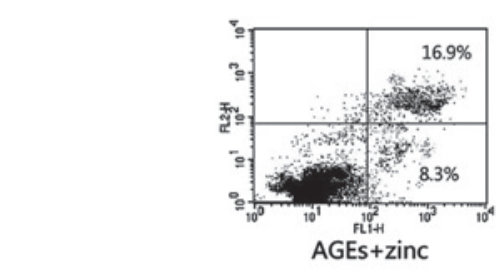

$\mathbf{F}$
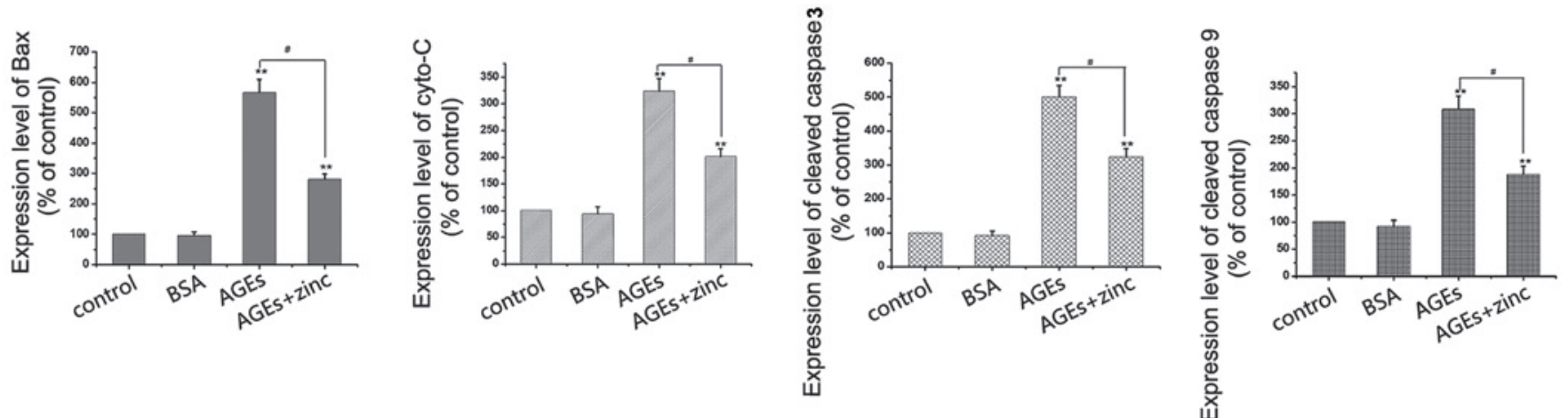

Figure 1. Effects of zinc on AGE-induced apoptosis in MC3T3-E1 mouse preosteoblast cells. (A) MC3T3-E1 cells were treated with AGEs (0-2,000 $\mu \mathrm{g} / \mathrm{ml})$ for 24, 48 and $72 \mathrm{~h}$. Following treatment, cell viability was detected using an MTT assay. Results are presented as a percentage of the inhibition of cell viability, which was calculated from the mean absorbance \pm standard deviation of triplicate samples. (B) MC3T3-E1 cells were treated with BSA or $500 \mu \mathrm{g} / \mathrm{ml}$ AGEs, in the presence or absence of 30 or $50 \mu \mathrm{M} \mathrm{ZnSO}_{4}$ for $48 \mathrm{~h}$, and cell viability was detected using an MTT assay. Values are presented as the mean \pm standard deviation of three independent experiments. ** $\mathrm{P}<0.01$, vs. control; ${ }^{~} \mathrm{P}<0.01$, vs. AGE group. (C) MC3T3-E1 cells were treated with BSA or $500 \mu \mathrm{g} / \mathrm{ml}$ AGEs, in the presence or absence of $50 \mu \mathrm{M} \mathrm{ZnSO}_{4}$, for $48 \mathrm{~h}$, and apoptosis was detected using flow cytometry following Annexin V-PI double staining. (D) Cells were treated, as described above, and cell morphology was observed under a microscope. Magnification, x400. (E) Cells were treated, as described above, and the protein expression levels of cytosolic cyto-C, mitochondrial Bax, and caspase-3 and caspase- 9 were detected using western blotting. (F) Values are presented as the mean \pm standard deviation of three independent experiments. $\beta$-actin was used as a loading control. ${ }^{* *} \mathrm{P}<0.01$, vs. control; ${ }^{\# P}<0.01 \mathrm{AGE}+$ zinc group, vs. AGE group. AGEs, advanced glycation end products; BSA, bovine serum albumin; PI, propidium iodide; cyto-C, cytochrome $c$; Bax, B-cell lymphoma 2-associated X protein.

Statistical analysis. Statistical analyses were performed using SPSS version 18 (SPSS Inc., Chicago, IL, USA). Data are expressed as the mean \pm standard deviation of at least three independent experiments. The variance was homogenous permitting the use of standard analysis of variance (ANOVA). Following determination of statistical significance using ANOVA, individual comparisons were made using Tukey's multiple comparison test. $\mathrm{P}<0.05$ was considered to indicate a statistically significant difference.

\section{Results}

Zinc protects MC3T3-E1 cells from AGE-induced apoptosis. AGEs induce cell apoptosis; however, whether AGEs induce 
A
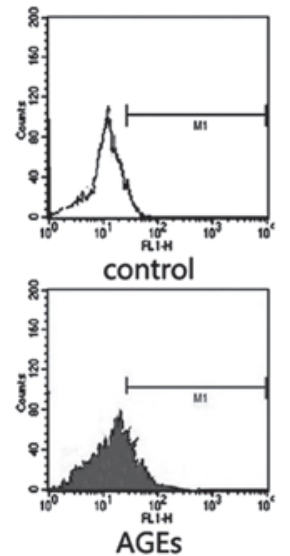

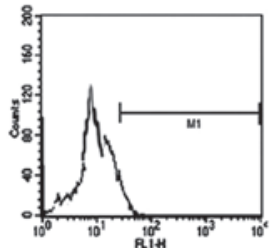

BSA

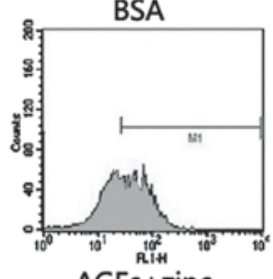

AGEs+zinc

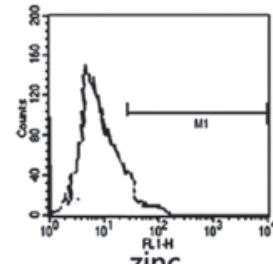

zinc

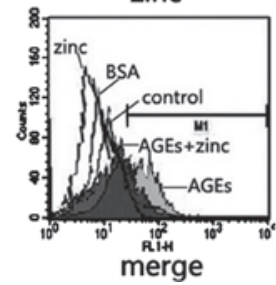

B

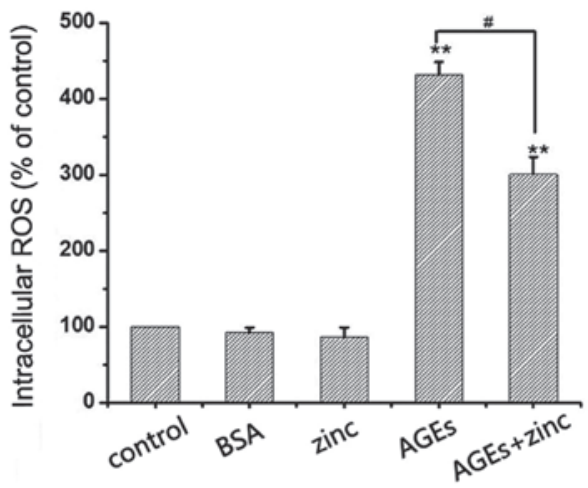

Figure 2. Zinc inhibits AGE-induced ROS production in MC3T3-E1 mouse preosteoblast cells. (A) MC3T3-E1 cells were treated with BSA, 50 $\mu \mathrm{M}_{\mathrm{ZnSO}} \mathrm{M}_{4}$ $500 \mu \mathrm{g} / \mathrm{ml}$ AGEs in the presence or absence of $50 \mu \mathrm{M} \mathrm{ZnSO}_{4}$ for $48 \mathrm{~h}$, and intracellular ROS levels were measured by flow cytometry using the DCFH-DA oxidation-sensitive fluorescent probe. (B) Levels of ROS are expressed as the mean \pm standard deviation and are representative of three independent experiments. ${ }^{* *} \mathrm{P}<0.01$, vs. control; " $\mathrm{P}<0.01$ AGE + zinc group, vs. AGE group. AGEs, advanced glycation end products; ROS, reactive oxygen species; BSA, bovine serum albumin; DCFH-DA, 2,7-dichlorodihydrofluorescein.

the apoptosis of mouse osteoblasts remains to be elucidated. To determine whether AGEs induce osteoblast apoptosis, the present study treated MC3T3-E1 cells with various doses of AGEs for 24, 48 and $72 \mathrm{~h}$. Cell viability assays demonstrated that the AGEs inhibited cell growth in a dose- and time-dependent manner (Fig. 1A). The half maximal inhibitory concentration values of AGEs in the MC3T3-E1 cells at 24, 48 and $72 \mathrm{~h}$ were 936, 725 and $590 \mu \mathrm{g} / \mathrm{ml}$, respectively. For subsequent experiments in the present study, $500 \mu \mathrm{g} / \mathrm{ml}$ AGEs were used (the concentration that apoptosis is clear). In order to determine the role of AGEs in promoting apoptosis and the anti-apoptotic effects of zinc, the MC3T3-E1 cells were treated with either BSA, or with $500 \mu \mathrm{g} / \mathrm{ml}$ AGEs in the presence or absence of 30 or $50 \mu \mathrm{M} \mathrm{ZnSO}_{4}$ for $48 \mathrm{~h}$, and cell viability was detected using an MTT assay. When treated with BSA alone, the MC3T3-E1 cells proliferated at the same rate as the control cells, whereas treatment with $500 \mu \mathrm{g} / \mathrm{ml}$ AGEs significantly suppressed the viability of the MC3T3-E1 cells. Notably, cells cultured with AGEs and zinc combined (30 or $50 \mu \mathrm{M}$ ) exhibited improved viability, compared with the AGE group (Fig. 1B). The percentage of apoptotic cells was markedly increased in the cells treated with AGEs, whereas zinc pretreatment resulted in a significant decrease in the percentage of apoptosis (Fig. 1C), as determined by flow cytometry. Similarly, cell survival was higher when the cells were exposed to AGEs and zinc combined, compared with the cells treated with AGEs alone, as observed in the inverted phase contrast microscopy images (SZ51; Olympus, Tokyo, Japan) (Fig. 1D). To further investigate the protective effects of zinc, western blotting was performed to detect the protein expression levels of caspase-3 and -9, cyto-C, and Bax. Treatment with zinc significantly downregulated the expression levels of mitochondrial cleaved-caspase-3, cleaved-caspase- 9 and Bax, and of cytosolic cyto-C, compared with the AGE group. These data indicated that AGEs induced MC3T3-E1 cell apoptosis, and that zinc may protect MC3T3-E1 cells from AGE-induced apoptosis.

Zinc inhibits MC3T3-E1 cells from AGE-induced ROS generation. A previous study demonstrated that high levels of glucose and AGEs increase intracellular ROS levels in renal cells, and contribute to the development and progression of diabetic renal injury (15). Furthermore, oxidative stress and apoptosis are closely associated. The present study investigated the effects of zinc on AGE-induced ROS generation. The MC3T3-E1 cells were treated with BSA, $50 \mu \mathrm{M} \mathrm{ZnSO}_{4}$, or $500 \mu \mathrm{g} / \mathrm{ml}$ AGEs, in the presence or absence of $50 \mu \mathrm{M} \mathrm{ZnSO}_{4}$, for $48 \mathrm{~h}$, and intracellular ROS levels were measured using flow cytometry. As shown in Fig. 2, cellular ROS levels were four-fold higher in the AGEs-treated cells, compared with the control, whereas zinc significantly reduced of AGE-induced DCF-sensitive cellular ROS (Fig. 2). These data indicated that zinc may inhibit AGE-induced apoptosis in MC3T3-E1 cells by decreasing oxidative stress.

Zinc inhibits apoptosis through mitogen-activated protein kinase (MAPK)/ERK signaling in MC3T3-E1 cells. Since MAPK/ERK is implicated in the triggering of anti-apoptotic signal transduction pathways, the present study investigated whether the integrity of the pathway was required for the anti-apoptotic effects of zinc. To provide further insight into this signaling pathway leading to the protection of apoptosis in AGE-induced MC3T3-E1 cells, a specific MEK1 inhibitor, PD98059, was used at a concentration stated in a previous study (16). Treatment with zinc effectively protected the cells from AGE-induced apoptosis; however, when the cells were pretreated with zinc and PD98059 together, the protective effects of zinc were attenuated. Furthermore, zinc significantly increased the expression levels of p-ERK in the AGE-treated cells; however, co-treatment with $20 \mu \mathrm{M}$ PD98059 effectively inhibited the upregulation of ERK phosphorylation. However, the expression levels of total-ERK were not altered significantly. Inhibition of the MEK pathway with PD98059 attenuated the protective effects of zinc, suggesting a role for the MAPK/ERK pathway in this effect (Fig. 3). These results suggested that the activation of ERK is a critical event in the anti-apoptotic effects of zinc in MC3T3-E1 cells.

Zinc inhibits apoptosis through phosphoinositide 3-kinase (PI3K)/AKT signaling in MC3T3-E1 cells. The PI3K/Akt 
A
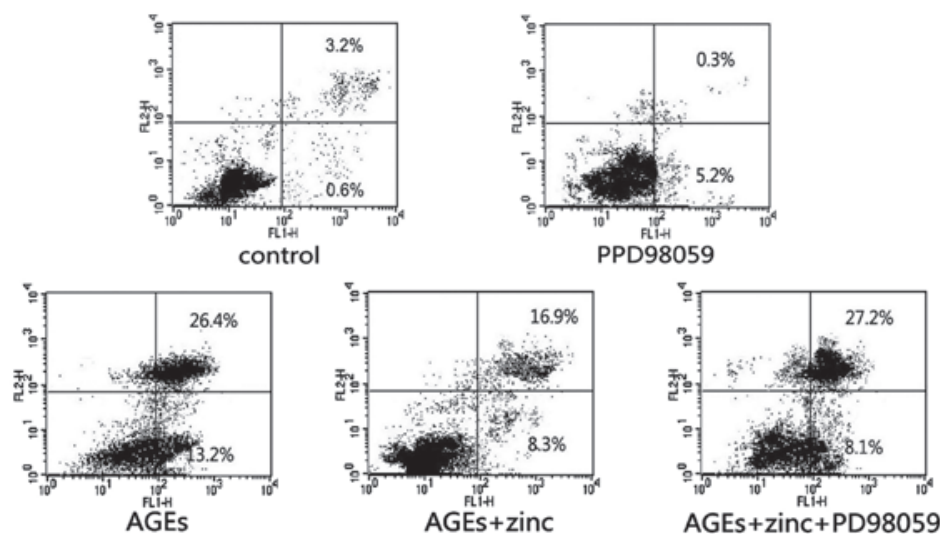

B
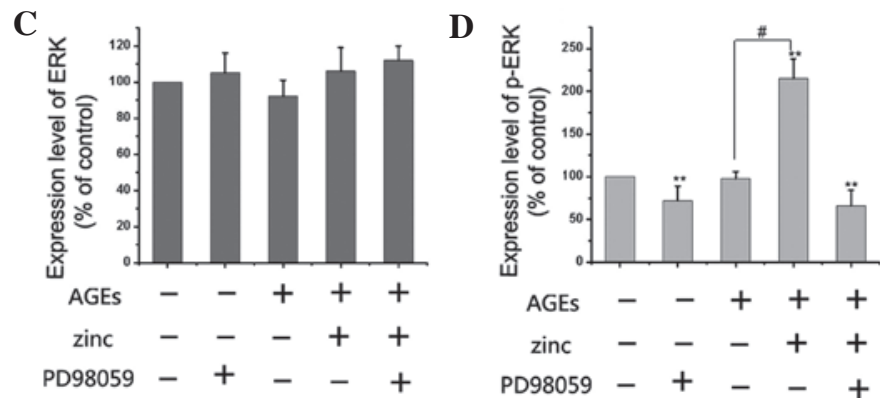

Figure 3. Effects of zinc on the ERK pathway in AGE-induced apoptosis. (A) MC3T3-E1 cells mouse preosteoblasts were incubated with or without $20 \mu \mathrm{M}$ PD98059 for $1 \mathrm{~h}$, and were then exposed to $500 \mu \mathrm{g} / \mathrm{ml}$ AGEs, in the presence or absence of $50 \mu \mathrm{M} \mathrm{ZnSO}_{4}$, for $48 \mathrm{~h}$. Apoptosis was determined using flow cytometry following Annexin V-PI double staining. (B) MC3T3-E1 cells were treated, as described above, and the expression levels of total ERK and p-ERK were detected using western blotting. Quantification of the expression levels of (C) total ERK and (D) p-ERK. Values are presented as the mean \pm standard deviation of three independent experiments. $\beta$-actin was used as loading control. ${ }^{* *} \mathrm{P}<0.01$, vs. control; ${ }^{*} \mathrm{P}<0.01$ AGE + zinc group, vs. AGE group. ERK, extracellular signal-regulated kinases; p-ERK; phosphorylated-ERK; AGEs, advanced glycation end products; PI, propidium iodide.

A

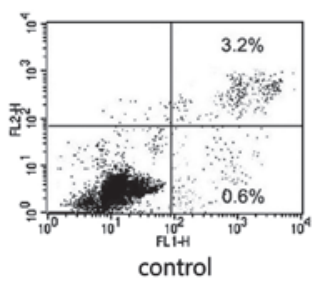

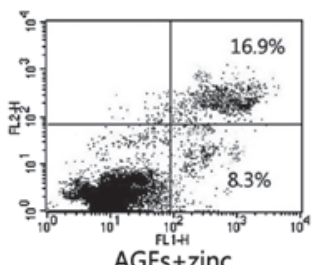

AGEs+zinc

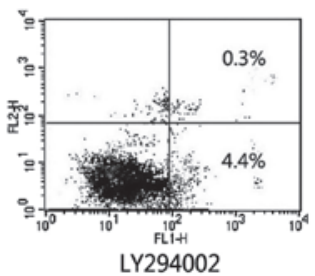

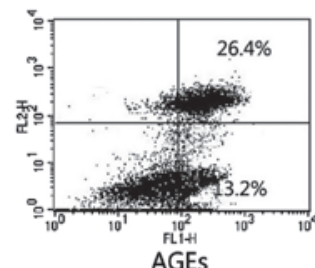

B

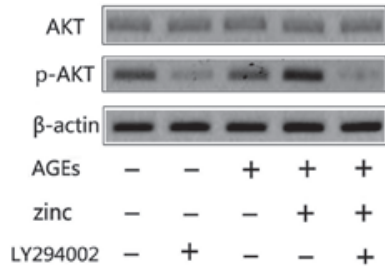

C

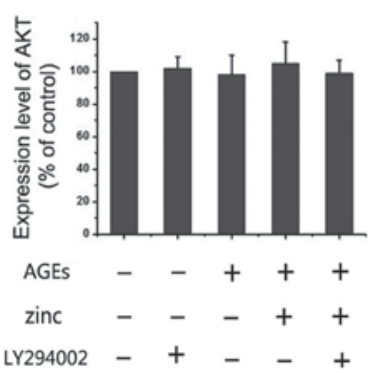

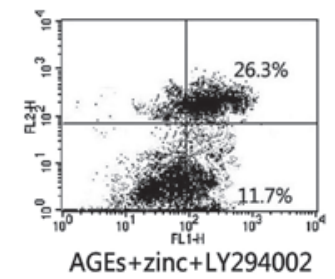

D

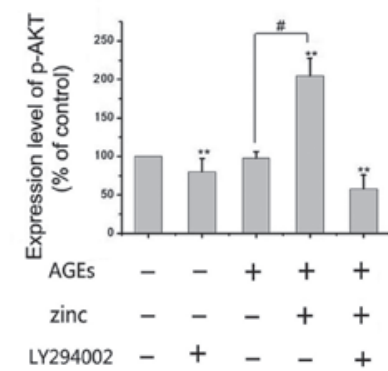

Figure 4. Effects of zinc on the AKT pathway in AGE-induced apoptosis. (A) MC3T3-E1 mouse preosteoblast cells were incubated with or without $10 \mu \mathrm{M} \mathrm{LY} 294002$ for $1 \mathrm{~h}$, and were then exposed to $500 \mu \mathrm{g} / \mathrm{ml} \mathrm{AGEs}$, in the presence or absence of $50 \mu \mathrm{M} \mathrm{ZnSO}_{4}$. Apoptosis was determined using flow cytometry following Annexin V-PI double staining. (B) MC3T3-E1 cells were treated, as described above, and the protein expression levels of total AKT and p-AKT were detected using western-blotting. Quantification of the expression levels of (C) total AKT and (D) p-AKT. Values are presented as the mean \pm standard deviation of three independent experiments. $\beta$-actin was used as a loading control. ${ }^{* *} \mathrm{P}<0.01$ vs. control; ${ }^{\text {}} \mathrm{P}<0.01$ AGE + zinc group, vs. AGE group. AGEs, advanced glycation end products; p-AKT, phosphorylated-AKT; PI, propidium iodide. 
pathway is a zinc-sensing process, which links extracellular survival signals with apoptosis-associated pathways and has a critical role in cell survival by inhibiting apoptotic pathways (17). In order to investigate the effects of this signaling pathway on the protection of apoptosis in AGE-induced MC3T3-E1 cells, a specific PI3K/AKT inhibitor, LY294002, was used, at a concentration stated in a previous study (18). Treatment with zinc effectively protected the cells from AGE-induced apoptosis; however, when the cells were pretreated with LY294002, the protective effects of zinc were attenuated. Furthermore, zinc significantly increased the expression levels of p-AKT in the AGE-treated cells; whereas co-treatment with $10 \mu \mathrm{M}$ LY294002 effectively inhibited the upregulation of AKT phosphorylation. The expression levels of total-AKT were not altered significantly. Furthermore, inhibition of the PI3K/AKT pathway by LY294002 attenuated the protective effects of zinc, suggesting a role for the PI3K/AKT pathway in this effect (Fig. 4). These results suggested that zinc protects cells from AGE-induced apoptosis through the PI3K/AKT pathway.

\section{Discussion}

Zinc is an essential trace element, which increases osteoblast proliferation and bone formation, and has been considered an important factor in bone metabolism (19). Zinc deficiency can alter the balance of bone remodeling, and low zinc intake has been reported to be associated with low bone mass in females (20). Therefore, it has been suggested that zinc supplementation may be a sustainable approach for the improvement of bone health. Fung et al (21) demonstrated that zinc supplementation results in a marked increase in total-body bone mass, compared with a placebo. Furthermore, zinc as an antioxidant may inhibit apoptosis. Kumar et al (22) demonstrated that zinc supplementation significantly decreases apoptosis and reduces the levels of ROS in the embryos of diabetic mice. The results of the present study revealed that pretreatment of cells with zinc markedly protected the cells from AGE-induced damage. Treatment with zinc decreased the production of intracellular ROS and significantly inhibited AGE-induced apoptosis of the MC3T3-E1 cells.

A previous study demonstrated that there are decreased bone levels of $\mathrm{Zn}^{2+}$ in postmenopausal females with osteoporosis, due to the reduction in osteoblast differentiation as bone mineralizing capacity decreases (20). Furthermore, a positive correlation has been detected between zinc levels and osteoprotegerin (OPG) levels in the serum $(20,23)$. Zinc increases osteogenic function by stimulating osteoblast proliferation and OPG activity (23). In addition, zinc is required for normal immune function and enhances the in vitro effectiveness of insulin. Impaired immune function has previously been reported in patients with diabetes, and decreased serum zinc levels and hyperzincuria occur in a number of diabetic patients and animals (24). Furthermore, diabetes results in increased oxidative stress, which is important in its pathogenesis. A previous study demonstrated that zinc supplementation in healthy volunteers resulted in a reduction in plasma levels of lipid peroxidation products, compared with a control group; therefore, zinc supplementation may have beneficial effects on glycemic control (25). In addition, zinc has been demonstrated to have a stimulatory effect on osteoblastic bone formation, and zinc compounds may be considered a novel supplementation factor for the prevention and treatment of diabetes-induced osteoporosis. A previous study demonstrated that cell viability and zinc levels were reduced following exposure to AGEs, and were improved with the supplementation of zinc in the endothelial cells (26). The results of the present study demonstrated that zinc inhibited the AGE-induced production of ROS and apoptosis in MC3T3-E1 cells.

Previous studies have demonstrated that the ERK and/or AKT pathways may contribute to the cell protective effects of several growth factors via apoptotic inhibition $(27,28)$. The present study investigated the possible signaling pathways that may mediate the protective effects of zinc in AGE-treated MC3T3-E1 cells. Western blot analysis demonstrated that zinc induced the phosphorylation of AKT and ERK in the MC3T3-E1 cells. In addition, treatment with PD98059 prevented the zinc-induced phosphorylation of ERK, and inhibited zinc-mediated anti-apoptotic effects (Fig. 3). Concordantly, treatment with the PI3K/Akt inhibitor, LY294002, inhibited zinc-induced AKT phosphorylation, suggesting that the PI3K/AKT pathway is involved with zinc-induced cell protection (Fig. 4). Therefore, it was concluded that zinc-mediated cell protection is associated with the ERK and AKT signaling pathways.

In conclusion, the results of the present study demonstrated that zinc exerted a cell protective effect against AGE-induced apoptosis in the MC3T3-E1 cells. The MAPK/ERK and $\mathrm{PI} 3 \mathrm{~K} / \mathrm{AKT}$ signaling pathways were found to be involved in the potent anti-apoptotic effects of zinc in AGE-treated cells. Although further investigations are required to determine the therapeutic effects of zinc in the protection of MC3T3-E1 viability and diabetic osteoporosis in vivo, these results indicate the potential of using zinc as a novel therapeutic strategy to treat the complications of diabetes, particularly osteoporosis.

\section{References}

1. Hof bauer LC, Brueck CC, Singh SK and Dobnig H: Osteoporosis in patients with diabetes mellitus. J Bone Miner Res 22: 1317-1328, 2007.

2. Das S and Crockett JC: Osteoporosis - a current view of pharmacological prevention and treatment. Drug Des Devel Ther 7: 435-448, 2013.

3. Schousboe JT, Tanner SB and Leslie WD: Definition of osteoporosis by bone density criteria in men: Effect of using female instead of male young reference data depends on skeletal site and densitometer manufacturer. J Clin Densitom 17: 301-306, 2014.

4. Rachner TD, Khosla S and Hofbauer LC: Osteoporosis: Now and the future. Lancet 377: 1276-1287, 2011.

5. Montagnani A, Gonnelli S, Alessandri $M$ and Nuti R: Osteoporosis and risk of fracture in patients with diabetes: An update. Aging Clin Exp Res 23: 84-90, 2011.

6. Lechleitner M, Pils K, Roller-Wirnsberger R, Beubler E, Gasser R, Mrak P, Hoppichler F and Pietschmann P: Diabetes and osteoporosis: Pathophysiological interactions and clinical importance for geriatric patients. Z Gerontol Geriatr 46: 390-397, 2013 (In German).

7. Wongdee $\mathrm{K}$ and Charoenphandhu N: Osteoporosis in diabetes mellitus: Possible cellular and molecular mechanisms. World J Diabetes 2: 41-48, 2011.

8. Watanabe R and Okazaki R: Diabetes mellitus and osteoporosis. Diabetes mellitus and bone and calcium metabolism. Clin Calcium 22: 1307-1314, 2012 (In Japanese).

9. Motyl KJ, McCauley LK and McCabe LR: Amelioration of type I diabetes-induced osteoporosis by parathyroid hormone is associated with improved osteoblast survival. J Cell Physiol 227: 1326-1334, 2012. 
10. Vlassara $\mathrm{H}$ and Uribarri J: Advanced glycation end products (AGE) and diabetes: Cause, effect, or both? Curr Diab Rep 14: 453, 2014.

11. Yamagishi S: Role of advanced glycation end products (AGEs) in osteoporosis in diabetes. Curr Drug Targets 12: 2096-2102, 2011.

12. Yamaguchi M: Role of nutritional zinc in the prevention of osteoporosis. Mol Cell Biochem 338: 241-254, 2010.

13. Zhang X, Zhao Y, Chu Q, Wang ZY, Li H and Chi ZH: Zinc modulates high glucose-induced apoptosis by suppressing oxidative stress in renal tubular epithelial cells. Biol Trace Elem Res 158: 259-267, 2014

14. Ruz M, Carrasco F, Rojas P, Codoceo J, Inostroza J, Basfi-fer K, Valencia A, Vásquez K, Galgani J, Pérez A, et al: Zinc as a potential coadjuvant in therapy for type 2 diabetes. Food Nutr Bull 34: 215-221, 2013.

15. Ha H and Lee HB: Reactive oxygen species and matrix remodeling in diabetic kidney. J Am Soc Nephrol 14 (8 Suppl 3): S246-S249, 2003.

16. Yan YX, Gong YW, Guo Y, Lv Q, Guo C, Zhuang Y, Zhang Y, Li R and Zhang XZ: Mechanical strain regulates osteoblast proliferation through integrin-mediated ERK activation. PLOS One 7: e35709, 2012.

17. Bruinsma JJ, Jirakulaporn T, Muslin AJ and Kornfeld K: Zinc ions and cation diffusion facilitator proteins regulate Ras-mediated signaling. Dev Cell 2: 567-578, 2002.

18. Park SJ, Kim SH, Choi HS, Rhee Y and Lim SK: Fibroblast growth factor 2-induced cytoplasmic asparaginyl-tRNA synthetase promotes survival of osteoblasts by regulating anti-apoptotic PI3K/Akt signaling. Bone 45: 994-1003, 2009.

19. Brzóska MM, Rogalska J, Galazyn-Sidorczuk M Jurczuk M, Roszczenko A, Kulikowska-Karpińska E and Moniuszko-Jakoniuk J: Effect of zinc supplementation on bone metabolism in male rats chronically exposed to cadmium. Toxicology 237: 89-103, 2007.

20. Gurban CV and Mederle O: The OPG/RANKL system and zinc ions are promoters of bone remodeling by osteoblast proliferation in postmenopausal osteoporosis. Rom J Morphol Embryol 52: (3 Suppl) 1113-1119, 2011.
21. Fung EB, Kwiatkowski JL, Huang JN, Gildengorin G, King JC and Vichinsky EP: Zinc supplementation improves bone density in patients with thalassemia: A double-blind, randomized, placebo-controlled trial. Am J Clin Nutr 98: 960-971, 2013.

22. Kumar SD, Vijaya M, Samy RP, Dheen ST, Ren M, Watt F, Kang YJ, Bay BH and Tay SS: Zinc supplementation prevents cardiomyocyte apoptosis and congenital heart defects in embryos of diabetic mice. Free Radic Biol Med 53: 1595-1606, 2012.

23. Liang D, Yang M, Guo B, Cao J, Yang L and Guo X: Zinc upregulates the expression of osteoprotegerin in mouse osteoblasts MC3T3-E1 through PKC/MAPK pathways. Biol Trace Elem Res 146: 340-348, 2012.

24. Niewoehner CB, Allen JI, Boosalis M, Levine AS and Morley JE: Role of zinc supplementation in type II diabetes mellitus. Am J Med 81: 63-68, 1986.

25. Jayawardena R, Ranasinghe P, Galappatthy P, Malkanthi R, Constantine $G$ and Katulanda P: Effects of zinc supplementation on diabetes mellitus: A systematic review and meta-analysis. Diabetol Metab Syndr 4: 13, 2012.

26. Zhuang X, Pang X, Zhang W, Wu W, Zhao J, Yang H and Qu W: Effects of zinc and manganese on advanced glycation end products (AGEs) formation and AGEs-mediated endothelial cell dysfunction. Life Sci 90: 131-139, 2012.

27. Wijesekara N, Krishnamurthy M, Bhattacharjee A, Suhail A, Sweeney G and Wheeler MB: Adiponectin-induced ERK and Akt phosphorylation protects against pancreatic beta cell apoptosis and increases insulin gene expression and secretion. J Biol Chem 285: 33623-33631, 2010.

28. García-Pérez AI, Galeano E, Nieto E, Estañ MC and Sancho P: Dequalinium induces cytotoxicity in human leukemia NB4 cells by downregulation of Raf/MEK/ERK and PI3K/Akt signaling pathways and potentiation of specific inhibitors of these pathways. Leuk Res 38: 795-803, 2014. 